\title{
Feruloylated Arabinoxylans from Maize Distiller's Dried Grains with Solubles: Effect of Feruloyl Esterase on their Macromolecular Characteristics, Gelling, and Antioxidant Properties
}

\author{
Jorge A. Marquez-Escalante *(i) and Elizabeth Carvajal-Millan *(i) \\ Biopolymers, Research Center for Food and Development (CIAD, AC), Carretera Gustavo Enrique Astiazarán \\ Rosas No. 46, Col. La Victoria, Hermosillo 83304, Sonora, Mexico \\ * Correspondence: marquez1jorge@gmail.com (J.A.M.-E.); ecarvajal@ciad.mx (E.C.-M.)
}

Received: 14 October 2019; Accepted: 12 November 2019; Published: 16 November 2019

\begin{abstract}
Distiller's dried grains with solubles (DDGS) are co-products of the maize ethanol industry. DDGS contains feruloylated arabinoxylans (AXs), which can present gelling, antioxidant, and health-promoting effects. However, AXs presenting high ferulic acid (FA) content can exhibit delayed fermentation by the colonic microbiota. Therefore, partial deferuloylation of AXs from DDGS while preserving the polysaccharide gelling and antioxidant properties could add value and favor the sustainable development of bioethanol plants. The aim of this work was to partially deferuloylated AXs from DDGS using feruloyl esterase and to evaluate the polysaccharide macromolecular characteristics, gelling, and antioxidant properties. The AXs presented FA and FA dimer contents of 3.27 and $0.30 \mu \mathrm{g} / \mathrm{mg}$ polysaccharide, respectively, which decreased to 1.26 and $0.20 \mu \mathrm{g} / \mathrm{mg}$ polysaccharide, respectively, in feruloyl esterase-treated AXs (FAXs). The molecular weight and intrinsic viscosity of FAXs were slightly less than those of AXs. The Fourier transform infrared spectroscopy data of AXs and FAXs were similar, confirming that the enzyme did not modify the polysaccharide molecular identity. FAX gels $(2 \% \mathrm{w} / \mathrm{v})$ exhibited a decrease in elasticity by $43 \%$ in relation to that of AXs gels. The antioxidant capacity of FAXs was reduced by $32 \%$ and $43 \%$ (DPPH and ABTS method, respectively), compared with that of AXs. The FAX gelling and antioxidant properties were -comparable to those reported for other AXs in the literature. Feruloyl esterase may offer an interesting approach for the design of functional FAXs as value-added products recovered from DDGS.
\end{abstract}

Keywords: cereal co-products; polysaccharides; ferulic acid; gels; antioxidants

\section{Introduction}

Maize is the largest source for bioethanol as a transportation fuel in areas such as the United States, the European Union, and China [1]. One of the significant co-products of the maize-based bioethanol generation is the distiller's dried grains with solubles (DDGS) fraction, which is usually utilized as a feed ingredient in animal production. DDGS have been previously investigated as a potential source of arabinoxylans (AXs) [2,3]. AXs are formed by a linear chain of $\beta-1,4$ xyloses, which may or may not be substituted by $\alpha-1,3$ and $\alpha-1,2$ arabinose units. Consequently, there may be three different forms of substitution: unsubstituted, mono-substituted, and di-substituted. The arabinose to xylose ratio $(\mathrm{A} / \mathrm{X})$ or degree of substitution refers to the number of arabinose units attached to the xylose backbone [4]. AXs can contain ferulic acid (FA) in their structure in such a way that some arabinose residues are ester-linked on O-5 to FA (Figure 1) [5]. The FA in AXs allows these polysaccharides to gel in the presence of specific oxidizing agents. AXs undergoing oxidative gelation was first reported by Durham [6] and Fausch et al. [7], demonstrating that the FA bonded with AXs is involved in this 
oxidative gelation. The gelling mechanism of AXs may implicate chemical $\left(\mathrm{FeCl}_{3}\right)$ or enzymatic (laccase and peroxidase $/ \mathrm{H}_{2} \mathrm{O}_{2}$ ) oxidizing agents, which induce the formation of phenoxy free radicals $[8,9]$. The coupling of these phenoxy free radicals results in the formation of dimers and trimers of FA, which allows the chains of polysaccharides to cross-link, forming an aqueous gel $[9,10]$. Laccase produce the oxidative cross-linking of phenolic compounds employing molecular oxygen as the final electron acceptor [11]. The AX gels are neutral, colorless, and odorless. Due to their covalent nature, these gels have interesting characteristics, such as high water absorption capacity and $\mathrm{pH}$, temperature, and ionic stability. These characteristics and their meso- and macroporous structure make AX gels highly suitable for the formulation of delivery systems of drugs in the colon [12]. AX gels present some advantages when compared to other polysaccharide gels. AX gels are quickly formed; their cross-links are much stronger and are stable when subjected to heat and $\mathrm{pH}$ changes and do not exhibit syneresis after prolonged storage [4]. The functional properties of AXs are related to their structural characteristics, such as their arabinose to xylose ratio $(\mathrm{A} / \mathrm{X})$, molecular weight $(\mathrm{M} w)$ and FA content. In this regard, several studies have focused on investigating the relative influence of each structural characteristic on AX properties by varying the AX source. In particular, the FA content has been considered to be of significant importance in AX gelling and in their antioxidant capability $[13,14]$. AXs extracted from DDGS can present health-promoting effects [2], which could add value and favor the sustainable development of bioethanol plants. Nevertheless, it has been reported that highly feruloylated AXs and FA-cross-linked AXs present a reduced rate of fermentation by colonic microbiota $[15,16]$. Therefore, partial deferuloylation of AXs extracted from DDGS while preserving the polysaccharide gelling and antioxidant properties would allow for the efficient utilization of this co-product. In this regard, partially deferuloylated AXs presenting sufficient gelling capabilities would be attractive, for example, for the preparation of efficient colon-targeted delivery systems exhibiting antioxidant characteristics.

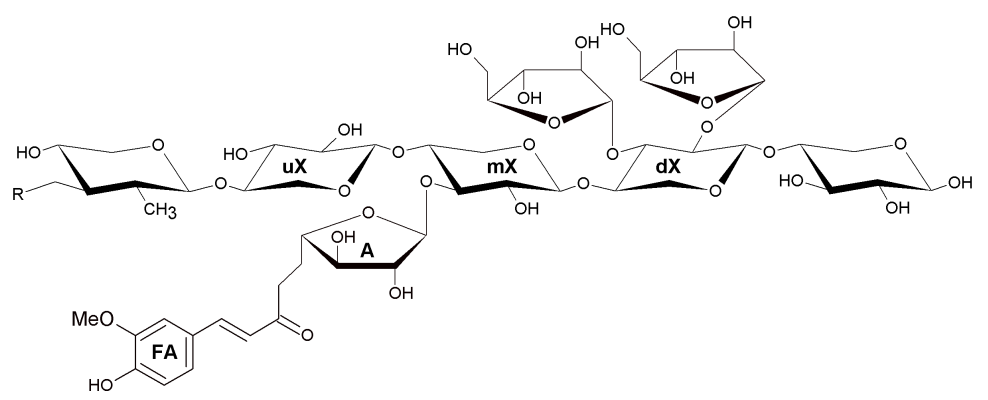

Figure 1. Basic structure of feruloylated arabinoxylans. Arabinose (A); ferulic acid (FA); unsubstituted xylose $(\mathrm{uX})$; monosubstituted xylose $(\mathrm{mX})$; disubstituted xylose $(\mathrm{dX})$.

Previous studies have reported the chemical modification of the FA content in AXs [12,17]. However, compared with chemical modification, enzymatic modification of the FA content in polysaccharides has the advantages of high specificity, high efficiency, and few side effects [18]. The use of feruloyl esterase to reduce the FA content in AXs extracted from ragi and wheat flours has been previously studied [19]. Those authors only reported a decrease in the relative viscosity of feruloyl esterase-treated AXs under peroxidase exposure. In this context, to the best of our knowledge, the modification of the FA content in AXs from DDGS using a feruloyl esterase has not been reported elsewhere. This work aimed to investigate the partial deferuloylation of FA in AXs from DDGS and to evaluate its effect on polysaccharide gelling and their antioxidant properties. This strategy could represent an alternative for the design of functional AXs as value-added products for the food and biomedical industry as well as an opportunity in sustainable food waste utilization. 


\section{Materials and Methods}

\subsection{Materials}

AXs were extracted from DDGS given by a feed supply manufacturer in the Northwest in Mexico. All chemical products and laccase (E.C. 1.10.3.2) from Trametes versicolor were bought from Sigma Chemical Co. (St Louis, MO, USA). Feruloyl esterase enzyme (E.C. 3.1.1.73) was a kind gift from Biocatalysts Limited (Cardiff, UK).

\subsection{Methods}

\subsubsection{Extraction of Feruloylated Arabinoxylans (AXs)}

AXs were extracted as previously reported [3]. In brief, DDGS (500 g) was treated with $2500 \mathrm{~mL}$ of absolute ethanol to remove the lipophilic components $\left(100 \mathrm{rpm}, 25^{\circ} \mathrm{C}, 12 \mathrm{~h}\right)$. The DDGS/ethanol mixture was filtered $(2.7 \mu \mathrm{m})$, and the recovered DDGS was then boiled in $3500 \mathrm{~mL}$ of water for $30 \mathrm{~min}$ and again filtered $(2.7 \mu \mathrm{m})$. Afterward, $2500 \mathrm{~mL}$ of $0.5 \mathrm{~N} \mathrm{NaOH}$ was mixed with the DDGS at $100 \mathrm{rpm}, 25^{\circ} \mathrm{C}$ for $30 \mathrm{~min}$ in darkness, and then acidified to $\mathrm{pH} 4$ with a $6 \mathrm{~N} \mathrm{HCl}$ solution. The mix was centrifuged at $12096 \mathrm{~g}, 20^{\circ} \mathrm{C}$ for $15 \mathrm{~min}$, and the supernatant was precipitated with $65 \%(\mathrm{v} / \mathrm{v})$ ethanol at $4{ }^{\circ} \mathrm{C}$ for $12 \mathrm{~h}$. The precipitate was dried by solvent exchange with $80 \% \mathrm{v} / \mathrm{v}$ ethanol, absolute ethanol, and acetone to obtain AXs.

\subsubsection{Partial Deferuloylation of AXs by Feruloyl Esterase}

Feruloyl esterase was selected because it cleaves the ester linkages of the carboxylic group in phenolic acids (ferulic and p-coumaric acid) and the C5-hydroxyl of the $\alpha$-L-arabinosyl side chains of xylans (Figure 2).

(a) Ferulated AX

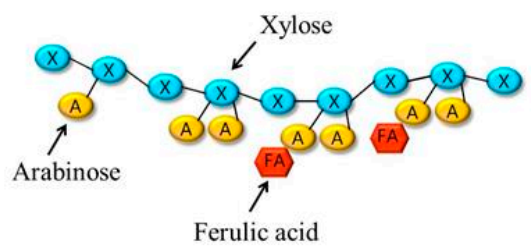

(a) Feruloyl esterase treatment of $\mathrm{AX}$

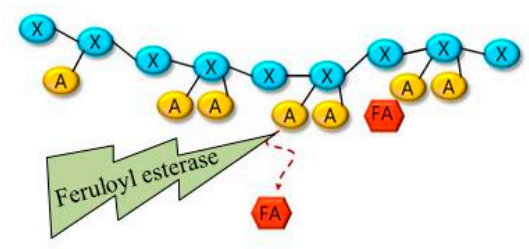

(c) Partially deferulated AX

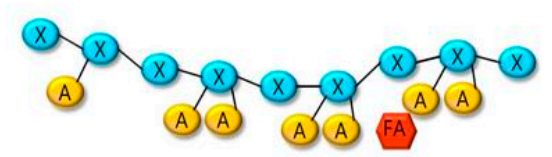

Figure 2. Schematic representation of partial AX deferuloylation by feruloyl esterase treatment.

Feruloyl esterase activity was measured by reverse-phase liquid chromatography using ethyl ferulate as a substrate. An assay mix $(1 \mathrm{~mL})$ containing the enzyme extract $\left(3 \times 10^{-3} \mathrm{mg} / \mathrm{mL}\right)$, ethyl ferulate $(5 \mathrm{mM})$ and MOPS $(100 \mathrm{mM}, \mathrm{pH}$ ) $)$ was incubated in darkness with gentle stirring at $40^{\circ} \mathrm{C}$ for $60 \mathrm{~min}$. The reaction was stopped by adding glacial acetic acid $(200 \mu \mathrm{L})$. The FA released in solution was recovered by adding ethyl acetate $(3 \mathrm{~mL}, 2 \times)$, centrifuged $\left(3820 \mathrm{~g}, 25^{\circ} \mathrm{C}, 5 \mathrm{~min}\right)$, and the supernatant was evaporated at $40{ }^{\circ} \mathrm{C}$ under nitrogen in the dark [20]. The recovered FA was suspended in a methanol:water:acetic acid (40:59:1) solution, filtered $(0.45 \mu \mathrm{m})$, and injected onto the 
HPLC system (Waters Co., Milford, MA, USA) at $25^{\circ} \mathrm{C}$. An analytical Supelcosil LC-18-BD column (Supelco Inc., Bellefont, USA) was used with an isocratic solution of methanol:water:acetic acid (40:59:1) at $0.6 \mathrm{~mL} / \mathrm{min}$. FA was detected by UV absorbance at $280 \mathrm{~nm}$ in a photodiode array detector (PDA) (Waters Co., Milford, MA, USA). The assay was carried out in triplicate. One unit (U) of activity was defined as the amount of enzyme releasing one $\mu$ mol of FA per minute at $\mathrm{pH} 6$ and $40^{\circ} \mathrm{C}$. For AX deferuloylation, a $\%(\mathrm{w} / \mathrm{v})$ AX solution was prepared in MOPS (100 mM, pH 6.0) and stirred at $4{ }^{\circ} \mathrm{C}$ for $12 \mathrm{~h}$. Feruloyl esterase was added to the AX solution (721 $\mu \mathrm{U}$ enzyme/mg polysaccharide) at $40{ }^{\circ} \mathrm{C}$ in the dark over $24 \mathrm{~h}$ with gentle stirring. The enzymatic reaction was stopped by adding glacial acetic acid $(1: 5 \mathrm{v} / \mathrm{v})$. The reaction mixture was precipitated in $75 \%(\mathrm{v} / \mathrm{v})$ ethanol at $4{ }^{\circ} \mathrm{C}$ for $12 \mathrm{~h}$. The precipitate was filtered and dried by solvent exchange with $80 \%(\mathrm{v} / \mathrm{v})$ ethanol, absolute ethanol, and acetone to obtain FAXs [12].

\subsubsection{FA, Dimers (di-FA) and Trimer of FA (tri-FA) Content}

After the saponification of the AXs and FAXs, the FA, dimers and trimer of FA content was quantified by reverse-phase liquid chromatography as mentioned before [9]. Two milliliters of $2 \mathrm{~N}$ $\mathrm{NaOH}$ was added to $50 \mathrm{mg}$ of AXs in a nitrogen-enriched atmosphere. The samples were incubated under agitation at $50 \mathrm{rpm}$ and $35^{\circ} \mathrm{C}$ for $2 \mathrm{~h}$ in darkness (KS 3000 ic control, IKA, Wilmington, NC, USA). Subsequently, $100 \mu \mathrm{L}$ of 3,4,5-trimethoxycinnamic acid (TMCA) and $5 \mathrm{~mL}$ of $4 \mathrm{~N}$ hydrochloric acid were added to both samples. The $\mathrm{pH}$ was adjusted to 2 . Phenolics were extracted twice with 5 $\mathrm{mL}$ of diethyl ether and then evaporated to dryness at $40^{\circ} \mathrm{C}$ under nitrogen gas (Dri-Block DB-3A, Techne, UK). The extract was recovered in $1 \mathrm{~mL}$ of methanol:water (50:50), filtered $(0.45 \mu \mathrm{m})$, and quantified using a chromatographic system (Waters Co, Milford, MA, USA). A Supelcosil LC-18-BD column (Supelco, Inc., Bellefonte, PA, USA) and a PDA (Waters Co, Milford, MA, USA) were used. Detection was achieved by measuring UV absorbance at $320 \mathrm{~nm}$.

\subsubsection{Macromolecular Characteristics}

The samples $\left(5 \mathrm{mg}\right.$ ) were mixed in $1 \mathrm{~mL}$ of $50 \mathrm{mM} \mathrm{NaNO} / 0.02 \% \mathrm{NaN}_{3}$ at $80{ }^{\circ} \mathrm{C}$ for $2 \mathrm{~h}$ with constant stirring. The biopolymer solutions were centrifuged at $15,000 \times g$ and $20^{\circ} \mathrm{C}$ for $10 \mathrm{~min}$. Once the supernatants were filtered $(0.21 \mu \mathrm{m})$, the samples were analyzed by size-exclusion high-performance liquid chromatography (SE-HPLC) with a multi-angle laser light scattering (MALLS) DAWN/HELEOS-II detector, an Optilab T-rex refractometer, and a ViscoStar-II viscometer (Wyatt Technology Corp., Santa Barbara, CA, USA). The SE-HPLC system consisted of two columns, Shodex OH-pak SBH-Q-804 and 805 columns (Shodex Showa Denco K.K., Tokyo, Japan), and a chromatographic system (Agilent Technologies, Inc., Santa Clara, CA, USA). The elution of AXs and FAXs was performed with $50 \mathrm{mM} \mathrm{NaNO} / 3.02 \% \mathrm{NaN}_{3}$ at $0.6 \mathrm{~mL} / \mathrm{min}$ and $25^{\circ} \mathrm{C}$. Weight average molecular weight $(\mathrm{Mw})$, intrinsic viscosity $([\eta])$, and polydispersity index $(P D I=\mathrm{M} w / \mathrm{M} n)$ were determined by Astra 6.1 software (Wyatt Technology Corp., Santa Barbara, USA). The $d n / d c$ value of $0.146 \mathrm{~mL} / \mathrm{g}$ previously reported for AXs was used [21].

\subsubsection{Fourier Transform Infrared Spectroscopy (FT-IR)}

The FT-IR spectrums of AXs and FAXs powder were recorded on a Nicolet iS50 FT-IR spectrophotometer (Nicolet Instrument Corp., Madison, WI, USA). The AXs and FAXs were placed on a smart iTX module, and the spectrums were recorded in the range of $4000-500 \mathrm{~cm}^{-1}$ with $4 \mathrm{~cm}^{-1}$ resolution and 32 scans [3]. OMNIC 9.3.32 software was used for data processing.

\subsubsection{Gelation}

AXs and FAXs $2 \%(\mathrm{w} / \mathrm{v})$ gels were formed at $25{ }^{\circ} \mathrm{C}$ using laccase as a cross-linking agent (1.675 nkat/mg polysaccharide) as described previously [16,22]. The gelation kinetics of the AXs and FAXs were monitored employed small-amplitude oscillatory shear analysis. Rheological measurements were carried out using a rheometer (Discovery HR-2, TA Instruments, New Castle, DE, USA) at $0.25 \mathrm{~Hz}$ 
and $5 \%$ strain for $1 \mathrm{~h}$. The mechanical spectrum of the gels was collected by a frequency sweep from 0.1 to $10 \mathrm{~Hz}$ at $5 \%$ strain. All measurements were carried out at $25^{\circ} \mathrm{C}$.

\subsubsection{Antioxidant Capacity}

The antioxidant capacity of the AXs and FAXs was measured by 2,2'-azinobis-(ethylbenzothiazoline-6-sulfonic acid) (ABTS) and 1,1-diphenyl-2-picryl-hydrazyl (DPPH) assays. The ABTS method was performed as previously reported. [23]. To prepared the ABTS radical cation $\left(\mathrm{ABTS}^{\bullet+}\right), 0.034 \mathrm{~g}$ of ABTS (concentration final of $7 \mathrm{mM}$ ) was mix with $10 \mathrm{~mL}$ of $2.45 \mathrm{mM}$ potassium persulfate, and keep at room temperature for approximately $16 \mathrm{~h}$. The $\mathrm{ABTS}^{\bullet+}$ was mixed with ethanol:water (50:50 v/v) until the absorbance was $0.7( \pm 0.02)$. One milligram of each sample (AXs and FAXs) were mixed with $6 \mathrm{~mL}$ of the $\mathrm{ABTS}^{\bullet+}$ reagent for $2 \mathrm{~min}$ and then centrifuged at $9200 \mathrm{~g}$ for $2 \mathrm{~min}$. The absorbance of the supernatant was measured at $734 \mathrm{~nm}$ at 7, 15, and $30 \mathrm{~min}$. The DPPH method was carried out, as described elsewhere [24]. The DPPH reagent $(1.8 \mathrm{mg})$ was dissolved in $50 \mathrm{~mL}$ methanol:water (60:40). The reaction medium was made as follows: $400 \mu \mathrm{L}$ sample $(2 \mathrm{mg} / \mathrm{mL})$, $250 \mu \mathrm{L}$ methanol, and $750 \mu \mathrm{L}$ DPPH (final concentration of $45 \mu \mathrm{M}$ ). The reaction medium was mixed and kept in the dark for $35 \mathrm{~min}$. The absorbance at $515 \mathrm{~nm}$ of the medium was measured at 40 and $60 \mathrm{~min}$. The antioxidant capacity was expressed as mmol of Trolox equivalent antioxidant capacity (TEAC) per kg of the sample using a dose-response curve of 0-20 $\mu \mathrm{M}$ for both the ABTS and DPPH methods. The analyses were carried out in triplicate.

\subsubsection{Statistical Analysis}

Chemical determinations were performed by triplicate with coefficients of variation lower than $7 \%$. Measurements of small deformation were made in triplicate with coefficients of variation lower than $9 \%$. All results are expressed as the mean values.

\section{Results}

\subsection{Extraction and Characterization of AXs}

AXs were extracted from $500 \mathrm{~g}$ of DDGS to yield $4.7 \%$ (w AXs/w DDGS) on a dry matter basis, which is higher than the value previously reported using $30 \mathrm{~min}$ of alkaline hydrolysis $(2.5 \% \mathrm{w} \mathrm{AXs} / \mathrm{w}$ DDGS) [3]. Extracted AXs consisted of white-colored powder with fine and granulated parts (Figure 3). AXs from cereal bran are water unextractable (WUAXs), as they present high molecular weights and a high FA content; however, after alkaline treatment under controlled conditions as those used in the present study, WUAXs from maize bran can be extracted in water. It is important to mention that AXs present in cereal endosperm are water extractable (WEAXs); however, the extraction of WEAXs is more expensive than that of the AXs used in the present study because the use of enzymes is required and extraction yields are lower ( $\sim .5 \% \mathrm{w} W E A X s / \mathrm{w}$ cereal endosperm), and the cereal endosperm is usually destined for human consumption, for example, in the production of wheat flour $[9,21]$. In contrast, in the present investigation, AXs extraction did not involve enzymes, the yield was higher, and the source was a maize co-product (DDGS from maize bioethanol plants).

The composition of AXs is shown in Table 1. The arabinose + xylose content in the AXs extracted from DDGS was $70.5 \%$ dry basis (db), which is higher than the value reported by other authors for AXs recovered from DDGS $(58.1 \%$ and $64.0 \%)[9,25]$. The arabinose to xylose ratio (A/X) was 0.7 , indicating a moderately branched structure in the range of that previously reported for AXs from DDGS (1.1 and 0.51) [9,25]. Small levels of glucose, galactose, and mannose were also quantified. The FA content $(3.27 \mu \mathrm{g} / \mathrm{mg} \mathrm{AXs})$ was lower than the value previously reported using $30 \mathrm{~min}$ of alkaline hydrolysis (7.53 $\mu \mathrm{g} / \mathrm{mg} \mathrm{AXs)}$ [3], which could be attributed to an extensive chemical de-esterification of FA during $1 \mathrm{~h}$ of alkaline hydrolysis used in the present work. However, the FA content reported in AXs extracted from DDGS is higher than that reported for AXs isolated from other maize co-products, such as maize wastewater generated during nixtamalization $(0.012-0.23 \mu \mathrm{g} / \mathrm{mg} \mathrm{AXs})$ [26]. These 
differences may be related to the partial de-esterification of FA attached to AX chains occurring during the cooking of maize grains under alkaline conditions. During maize bioethanol production, no chemical treatment is involved, allowing for better preservation of FA in the AX molecules. The di-FA and tri-FA contents in the AXs were 0.27 and $0.01 \mu \mathrm{g} / \mathrm{mg}$ AXs, respectively. The presence of di-FA and tri-FA in AXs from different cereals has been previously reported and are related to the possible presence of cross-linked AXs chains [3]. The di-FA structures present in AXs were 8-5', 5'-5' and 8-O-4' at 68,31 , and $1 \%$, respectively, while the $8-8^{\prime}$ di-FA was not detected. The high proportion of $8-5^{\prime}$ and $5^{\prime}-5^{\prime}$ di-FA structures in maize AXs has been indicated in earlier investigations $[3,22]$. In cell walls, the $8-5^{\prime}$ dimmer has been reported to be the most abundant di-FA due to the relatively high reactivity of its radical structures [12].

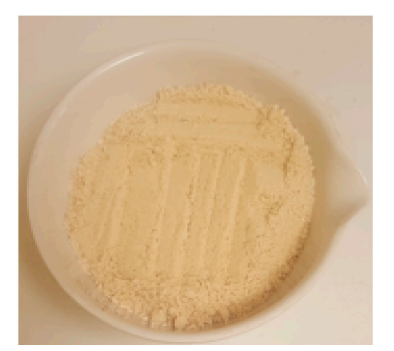

Figure 3. AXs extracted from DDGS.

Table 1. Composition of AXs extracted from DDGS.

\begin{tabular}{cc}
\hline Arabinose $^{\mathrm{a}}$ & $28.81 \pm 1.30$ \\
Xylose $^{\mathrm{a}}$ & $41.70 \pm 1.95$ \\
Glucose $^{\mathrm{a}}$ & $3.36 \pm 0.31$ \\
Galactose $^{\mathrm{a}}$ & $4.20 \pm 0.06$ \\
Mannose $^{\mathrm{a}}$ & $0.96 \pm 0.07$ \\
Protein $^{\mathrm{a}}$ & $3.20 \pm 0.05$ \\
Ferulic acid $^{\mathrm{b}}$ & $3.27 \pm 0.46$ \\
Diferulic acid $^{\mathrm{b}}$ & $0.30 \pm 0.02$ \\
Triferulic acid $^{\mathrm{b}}$ & $0.010 \pm 0.001$
\end{tabular}

${ }^{a}$ Values expressed in g/100 g $\overline{\mathrm{AXs} \text { dry matter. }{ }^{\mathrm{b}} \text { Phenolics are expressed in } \mu \mathrm{g} / \mathrm{mg} \mathrm{AX}}$ s dry matter. All results were obtained from triplicate analyses.

\subsection{Partial Deferuloylation of AXs by Feruloyl Esterase}

The initial FA content in the AXs $(3.27 \mu \mathrm{g} / \mathrm{mg}$ polysaccharide) decreased to $1.26 \mu \mathrm{g} / \mathrm{mg}$ polysaccharide when the sample was treated with feruloyl esterase, indicating that $61.5 \%$ of the FA esterified to the AX chains was removed. In the present study, the AXs and FAXs presented an average FA residue content of 5 and 2 FA molecules per 1000 xylose units, respectively. Previous investigations have reported 6-2 FA molecules per 1000 xylose residues in AXs from wheat, rye, triticale, and barley [4]. By using chemical de-esterification (lime treatment), a range of wheat flour AX samples with FA contents varying from 2.3 to $0.1 \mu \mathrm{g} / \mathrm{mg}$ AXs was prepared, which corresponded to FA residue contents from 2.5 to 0.1 molecules per 1000 xyloses, respectively [12]. Those authors found that in AXs the minimal FA content to gelling is $0.5 \mathrm{FA}$ residues per 1000 xyloses. However, in the present study, it was not possible to decrease the FA content in AXs beyond $1.26 \mu \mathrm{g} / \mathrm{mg}$ polysaccharide (2 FA molecules per 1000 xylose units) even at longer feruloyl esterase incubation times, which could be attributed to the high arabinose substitution degree $(\mathrm{A} / \mathrm{X}=0.7)$ in relation to the value reported in the study using chemical de-esterification $(\mathrm{A} / \mathrm{X}=0.6)$ [12]. A high amount of branched arabinose molecules from the xylose backbone may make feruloyl esterase access to de-esterification sites difficult. The di-FA content in the FAXs was $0.20 \mu \mathrm{g} / \mathrm{mg}$ polysaccharide, suggesting that some polysaccharide chains might be cross-linked [3,21]. The comparative percentages of each di-FA in FAXs were $58 \%$, $36 \%$, and $3 \%$ for $8-5^{\prime}, 5^{\prime}-5^{\prime}$ and $8-O-4^{\prime}$, respectively. 
The macromolecular characteristics of FAXs were not significantly affected by feruloyl esterase treatment (Table 2). The Mw and $[\eta]$ values in the FAXs slightly decreased in comparison to those of the AXs, probably related to the small decrease in the di-FA content from 0.30 to $0.20 \mu \mathrm{g} / \mathrm{mg}$ polysaccharide, which suggests a low amount of cross-linked AX chains in the sample.

Table 2. Macromolecular characteristics of AXs and FAXs.

\begin{tabular}{|c|c|c|c|}
\hline Sample & $\begin{array}{l}\text { Molecular weight } \\
\text { Mw (kDa) }\end{array}$ & $\begin{array}{l}\text { Polydispersity index } \\
\quad P D I=(M w / M n)\end{array}$ & $\begin{array}{c}\text { Intrinsic viscosity } \\
{[\eta](\mathrm{mL} / \mathrm{g})}\end{array}$ \\
\hline $\mathrm{AXs}$ & 270 & 1.2 & 100 \\
\hline FAXs & 250 & 1.2 & 95 \\
\hline
\end{tabular}

Coefficients of variation $<7 \%$.

The SE-HPLC chromatograms of the AXs and FAXs are presented in Figure 4. The Mw values found for AXs and FAXs in the present work were lower than those previously published for other AXs from DDGS in the literature (5900-4463 kDa) [9], possibly due to the mobile phase used by these authors (water). It has been reported that the chromatogram shape and the repeatability of retention time are considerably enhanced when the water is changed by sodium nitrate as the mobile phase [27]. The AXs and FAXs exhibited an index of polydispersity in the range reported for other AXs isolated from DDGS (1.0-1.8) (1.3-1.7). The elution profile of the FAXs was almost to the same as that of the AXs, showing that enzymatic treatment did not depolymerize the polysaccharide backbone (Figure 4). The $\mathrm{M} w$, I, and [ $\eta]$ values of AXs and FAXs were in the range reported for other maize-derived AXs in the literature $[3,9,22,28]$.

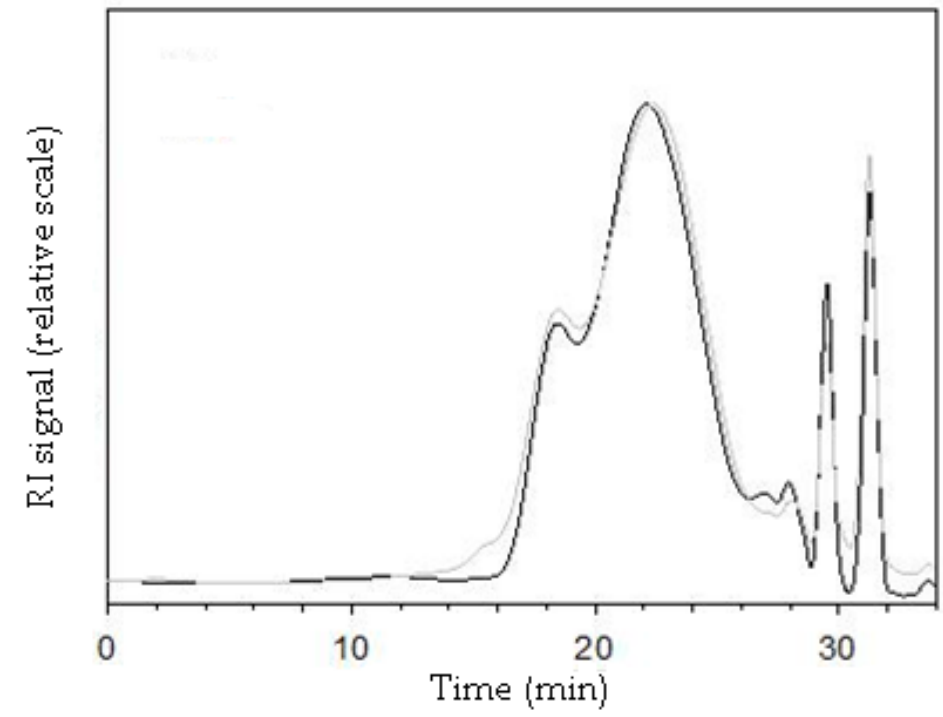

Figure 4. SE-HPLC chromatograms of AXs (一) and FAXs (一). RI: refractive index.

The FT-IR spectra (4000-400 $\mathrm{cm}^{-1}$ ) of the AXs and FAXs were very similar, confirming that feruloyl esterase releases FA without altering the molecular identity of this polysaccharide (Figure 5a). The $1200-900 \mathrm{~cm}^{-1}$ interval (fingerprint region) displays the typical spectra for xylan-type polysaccharides (Figure $5 b$ ). This region of the spectrum is constituted by absorption bands of C-O and C-C stretching and C-OH bending vibrations of the polymer backbone [29]. Both signals at $1164 \mathrm{~cm}^{-1}$ (denoted as the shoulder) and $1120 \mathrm{~cm}^{-1}$ (not defined as the shoulder) are assigned to $\mathrm{C}-\mathrm{O}$ and $\mathrm{C}-\mathrm{C}$ stretching vibrations. A ring vibration produces the shoulder at $1073 \mathrm{~cm}^{-1}$, and the dominant band at 1038 $\mathrm{cm}^{-1}$ is due to $\mathrm{COH}$ side groups [30]. The band at $990 \mathrm{~cm}^{-1}$ is not perceptible, suggesting a high arabinose side substitution (O-3 position) on the xylan backbone. The band at $905 \mathrm{~cm}^{-1}$ is related to the glycosidic $\mathrm{C} 1-\mathrm{H} 1$ deformation mode with ring vibration contribution and $\mathrm{OH}$ bending vibration, 
which confirms the $\beta-1,4$ glycosidic bond between the xylopyranose units of the main xylan chains [31]. A chain of simple xylopyranose units should not have visible absorption bands at $1800-1500 \mathrm{~cm}^{-1}$ (Figure 5c). Consequently, the bands in this region could be attributed to the vibration of a diverse type of substituent in the main chain or the xylan side chains [31]. In this regard, a band at $1645 \mathrm{~cm}^{-1}$ that mostly corresponds to polypeptide carbonyl stretching (amide I) [29] was also identified, confirming the presence of residual protein in the samples [3]. This band overlaps with the secondary absorption bands of FA $\left(1690,1620\right.$, and $\left.1600 \mathrm{~cm}^{-1}\right)$ [31]. The primary absorption band of FA is an assignment at $1517 \mathrm{~cm}^{-1}$, in our case, at $1519 \mathrm{~cm}^{-1}$ [30]. However, in the present study, this band is not clear due to overlap with the band at $1540 \mathrm{~cm}^{-1}$, which could be related to amide II [29]. As Figure $5 \mathrm{c}$ shows, the band at $1645 \mathrm{~cm}^{-1}$ is more defined, and consequently the band at $1540 \mathrm{~cm}^{-1}$ is relatively more intensive in the AX spectrum than in the FAX spectrum, which could be associated with the higher FA content in AXs in relation to FAXs. The broadband with a maximal signal at $3346 \mathrm{~cm}^{-1}$ is related to the vibration of hydroxyls involved in both intra- and intermolecular hydrogen bonds (Figure 5a) [31]. The bands at 2928 and $2875 \mathrm{~cm}^{-1}$ correspond to asymmetric and symmetric stretch vibrations of $\mathrm{CH}_{2}$ groups, respectively (Figure 5a). These vibrations could be explained by the presence of such groups in xylopyranose rings of the backbone xylan [32].

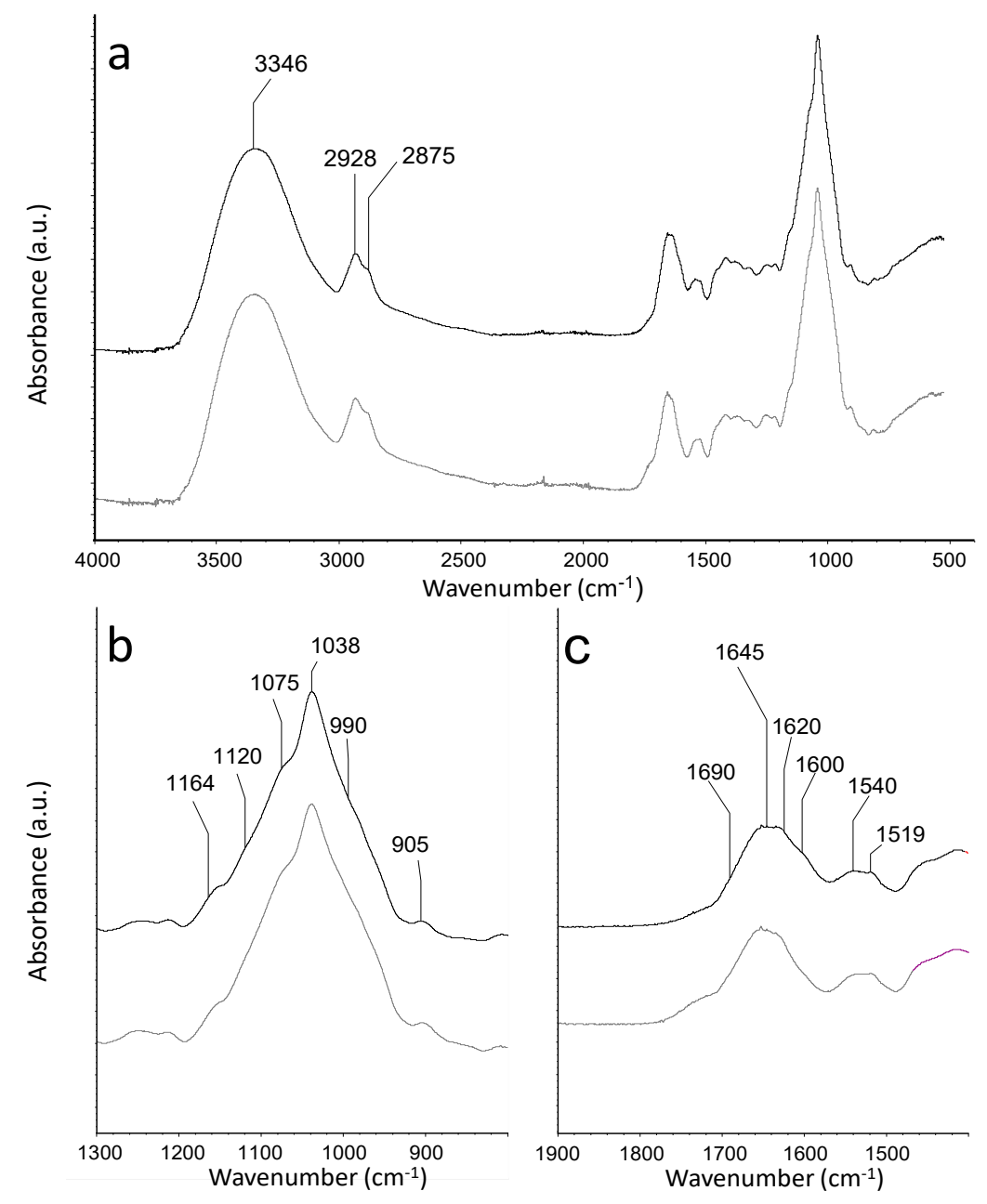

Figure 5. FT-IR spectra of AXs (-) and FAXs (-) at 4000-500 $\mathrm{cm}^{-1}(\mathbf{a}), 1200-900 \mathrm{~cm}^{-1}(\mathbf{b})$, and $1800-1500 \mathrm{~cm}^{-1}$ (c).

\subsection{AX and FAX Gelling and Antioxidant Properties}

The kinetics of the gelation of AXs and FAXs was rheologically investigated by small-amplitude oscillatory shear analysis. Similar gelation kinetics were observed for both samples with a lag time 
( $\sim 5 \mathrm{~min}$ ) followed by a rapid $\mathrm{G}^{\prime}$ rise until nearly constant values (plateau region) (Figure $\left.6 \mathrm{a}\right)$. The final $\mathrm{G}^{\prime}$ values for the AXs and FAXs gels (at $3600 \mathrm{sec}$ ) were $195 \mathrm{~Pa}$ and $112 \mathrm{~Pa}$, respectively. The gelation time $\left(G^{\prime}=G^{\prime \prime}\right)$ was lower in the AXs gel $(13 \mathrm{~min})$ than in the FAX gel $(16 \mathrm{~min})$. The $\mathrm{G}^{\prime}$ value decreased, and the gelation time was higher for the FAXs gel that for the AXs gel, which is related to the partial removal of FA in the molecule after feruloyl esterase treatment. These results were similar to those reported for gels obtained from wheat endosperm AXs, which were partially de-esterified by a chemical process [12], confirming the fundamental role of FA in the elastic properties of AXs gels. The mechanical spectra of the AXs and FAXs gels after $1 \mathrm{~h}$ of gelation are presented in Figure $6 \mathrm{~b}$. The AXs and FAXs gels exhibited typical gel behavior, with $G^{\prime}$ being independent of frequency and higher than G" [33]. Lower G' values were observed for FAXs gels than for AXs gels under the frequency range used in the present study. Nevertheless, the G" values were almost superposed for both samples, indicating that the viscous contribution to the gel structure was similar. From the $G^{\prime}$ and $G^{\prime \prime}$ values in the AXs and FAXs gels at $1 \mathrm{~Hz}$ the frequency used during polysaccharide gelation, tan delta $\left(G^{\prime \prime} / G^{\prime}\right)$ values were calculated. The tan delta values increased from 0.004 to 0.005 when the AX initial FA content was reduced from 3.27 to $1.26 \mu \mathrm{g} / \mathrm{mg}$ AXs. This change in the tan delta value means an increase in the flexibility of the polymer chain of the gel [34]. These mechanical spectra are similar to others reported for wheat- and maize-derived AX gels $[3,12,20]$. These results demonstrate that even when the FAX gel exhibited a reduction in its $\mathrm{G}^{\prime}$ value in relation to that of the AXs gel, the gel rheological characteristics are similar to those reported for other AXs gels in the literature $[3,12,20]$.

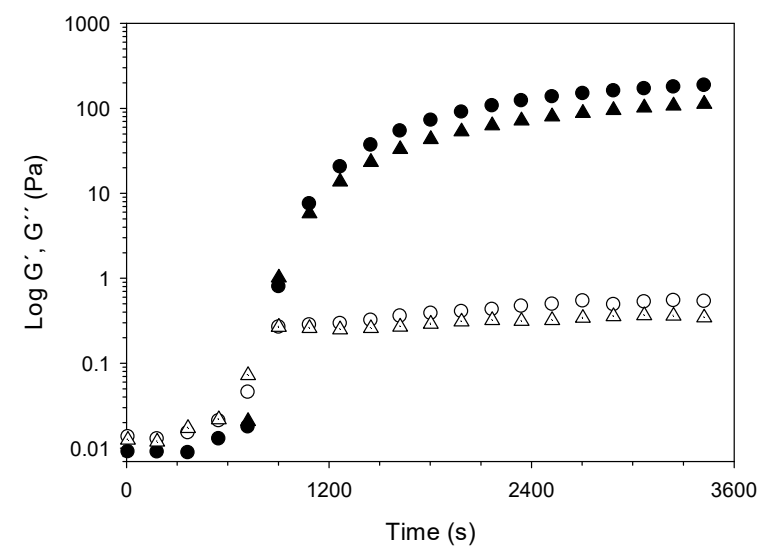

(a)

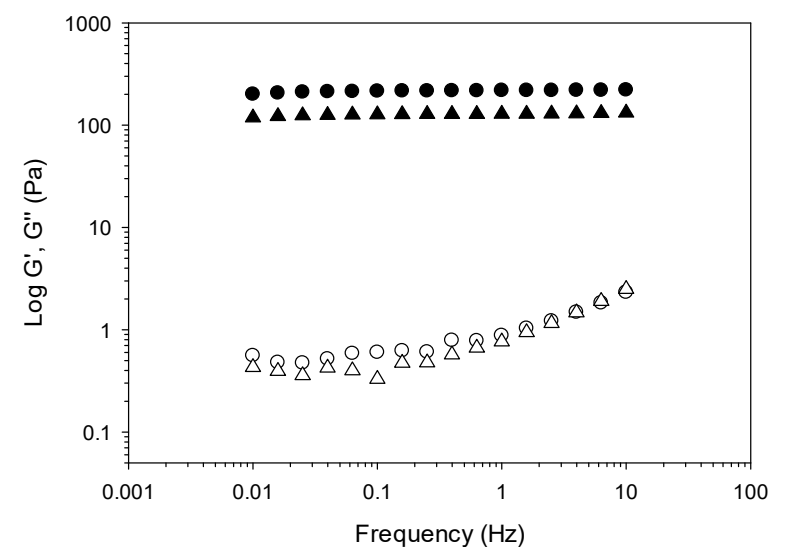

(b)

Figure 6. (a) Monitoring the storage modulus $\left(G^{\prime}\right)$ and loss modulus $\left(G^{\prime \prime}\right)$ of $2 \%(w / v)$ AX and FAX solutions during gelation by laccase $\left(25^{\circ} \mathrm{C}, 1 \mathrm{~Hz}\right.$, and $5 \%$ strain). (b) Mechanical spectra of AX and FAX gels induced by laccase $\left(25^{\circ} \mathrm{C}\right.$ and $5 \%$ strain). AX gel (circle), FAX gel (triangle), $\mathrm{G}^{\prime}$ (filled symbol), and G" (empty symbol).

The TEAC values of AXs and FAXs are shown in Table 3, as determined by the procedures using DPPH and ABTS solutions. Higher antioxidant activity values were observed when using ABTS than when using the DPPH method. It has been previously reported that ABTS is an unstable radical cation that reacts with antioxidants to generate compounds with antioxidant activity, thus leading to the overestimation of the antioxidant activity in a sample. In contrast, the relatively stable radical DPPH can be easily reduced by extracting hydrogen from hydrogen donors [35]. The results show that the partial deferuloylation of AXs reduced their antioxidant activity by $36 \%$ and $42 \%$ using the DPPH and ABTS methods, respectively. This reduction in antioxidant activity in FAXs may be attributed to the partial release of FA esterified to the polysaccharide. A previous study reported that AXs with a high amount of FA residues show high antioxidant activity [36]. The effect of Mw on the antioxidant activity of AXs is not clear. It has been suggested that a decrease in AX M $w$ could improve their antioxidant activity due to their higher solution mobility and, thus, their enhanced radical-scavenging activity [36]. 
Another study showed that in AXs, a higher Mw gave stronger antioxidant activity [37]. However, in the present study, feruloyl esterase treatment reduced the M $w$ of the AXs by only 7\% (Table 2). Thus, the polysaccharides still had a relatively high $\mathrm{M} w$; in this regard, the Mw the AXs did not seem to impact their antioxidant activity. The antioxidant capacity values obtained for the AXs and FAXs are in the range reported for other AXs from DDGS (12-68 mmol TEAC/ $\mathrm{kg})[17,38]$ and higher than those reported in AXs from other maize co-products $(6-16 \mathrm{mmol} \mathrm{TEAC} / \mathrm{kg})[14,39]$. The results suggested that AXs and FAXs have great potential as free-radical scavengers in the food, pharmaceutical, medical, and cosmetic industries, among others.

Table 3. Antioxidant capacity of AXs and FAXs.

\begin{tabular}{ccc}
\hline Sample & DPPH $(\mathbf{m m o l}$ TEAC/kg) & ABTS (mmol TEAC/kg) \\
\hline AXs & $28 \pm 2$ & $67 \pm 6$ \\
FAXs & $18 \pm 3^{*}$ & $39 \pm 3^{*}$ \\
\hline
\end{tabular}

All values are the mean \pm standard deviation of three repetitions. ${ }^{*}$ Value in each column is significantly different at $p \leq 0.001$.

\section{Conclusions}

AXs from DDGS can be partially deferuloylated by feruloyl esterase treatment, allowing for a reduction of $61.5 \%$ in FA content without affecting the polysaccharide molecular identity. The molecular weight and intrinsic viscosity of feruloyl esterase-treated AXs (FAXs) are slightly reduced, probably due to the decrease in di-FA content, which could moderate the presence of cross-linked polysaccharide chains. FAXs present gelling and antioxidant properties similar to those reported for other maize-derived AXs in the literature. FAX gels $(2 \% \mathrm{w} / \mathrm{v})$ exhibit a storage modulus value $43 \%$ lower than that of AXs gels at the same polysaccharide concentration. The antioxidant capacity of the FAXs is diminished by $32 \%$ and $43 \%$ using the DPPH and ABTS methods, respectively, in relation to that of AXs. These results confirm the fundamental part of FA in the gelling capability and antioxidant activity of this polysaccharide. Feruloyl esterase treatment could offer an exciting opportunity for the reliable design of AXs as value-added products for the food and biomedical industries as well as an opportunity in sustainable maize waste utilization. FAXs would be attractive as designed encapsulating and radical scavenging agents, for example, for the preparation of efficient colon-targeted delivery systems without the reduced rate of fermentation by the colonic microbiota.

Author Contributions: Conceptualization, J.A.M.-E. and E.C.-M.; Methodology, J.A.M.-E. and E.C.-M.; Validation, J.A.M.-E. and E.C.-M.; Formal Analysis, J.A.M.-E. and E.C.-M.; Investigation, J.A.M.-E. and E.C.-M.; Writing-Original Draft Preparation, J.A.M.-E.; Writing-Review and Editing, E.C.-M.; Visualization, J.A.M.-E. and E.C.-M.; Supervision, E.C.-M.; Project Administration, E.C.-M.; Funding Acquisition, E.C.-M.

Funding: This research was funded by 'Fund to support research on the Sonora-Arizona region 2019', Mexico (Grant 20614to E. Carvajal-Millan).

Acknowledgments: The authors are pleased to acknowledge Itzel Aguirre-Franco, Alma C. Campa-Mada, and Karla G. Martínez-Robinson (CIAD) for technical support.

Conflicts of Interest: The authors declare no conflict of interest.

\section{References}

1. Cheng, J.J.; Timilsina, G.R. Status, and barriers of advanced biofuel technologies: A review. Renew. Energy 2011, 36, 3541-3549. [CrossRef]

2. Carvajal-Millan, E.; Vargas-Albores, F.; Fierro-Islas, J.M.; Gollas-Galván, T.; Magdaleno-Moncayo, D.; Rascon-Chu, A.; Martínez-Porchas, M.; Lago-Lestón, A. Arabinoxylans and gelled arabinoxylans used as anti-obesogenic agents could protect the stability of intestinal microbiota of rats consuming high-fat diets. Int. J. Food Sci. Nutr. 2019. [CrossRef] [PubMed] 
3. Mendez-Encinas, M.A.; Carvajal-Millan, E.; Yadav, M.P.; López-Franco, Y.L.; Rascon-Chu, A.; Lizardi-Mendoza, J.; Brown-Bojorquez, F.; Silva-Campa, E.; Pedroza-Montero, M. Partial removal of protein associated with arabinoxylans: Impact on the viscoelasticity, crosslinking content, and microstructure of the gels formed. J. Appl. Polym. Sci. 2019, 136, 47300. [CrossRef]

4. Izydorczyk, M.S.; Biliaderis, C.G. Cereal arabinoxylans: Advances in structure and physicochemical properties. Carbohydr. Polym. 1995, 28, 33-48. [CrossRef]

5. Smith, M.M.; Hartley, R.D. Occurrence and nature of ferulic acid substitution of cell-wall polysaccharides in graminaceous plants. Carbohydr. Res. 1983, 118, 65-80. [CrossRef]

6. Durham, R.K. Effect of hydrogen peroxide on relative viscosity measurements of wheat and flour suspensions. Cereal Chem. 1925, 2, 297-305.

7. Faush, H.; Kunding, W.; Neukom, H. Ferulic acid as a component of glycoprotein from wheat flour. Nature 1963, 199, 287. [CrossRef]

8. Izydorczyk, M.S.; Biliaderis, C.G.; Bushuk, W. Oxidative gelation studies of water-soluble pentosans from wheat. J. Cereal Sci. 1990, 11, 153-169. [CrossRef]

9. Figueroa-Espinoza, M.C.; Rouau, X. Oxidative cross-linking of pentosans by a fungal laccase and horseradish peroxidase: Mechanism of linkage between feruloylated arabinoxylans. Cereal Chem. 1998, 75, 259-265. [CrossRef]

10. Geissman, T.; Neukom, H. On the composition of water soluble wheat flour pentosans and their oxidative gelation. LWT-Food Sci. Technol. 1973, 6, 54-62.

11. Selinheimo, E.; Autio, K.; Kruus, K.; Buchert, J. Elucidating the mechanism of laccase and tyrosinase in wheat bread making. J. Agric. Food Chem. 2007, 55, 6357-6365. [CrossRef] [PubMed]

12. Carvajal-Millan, E.; Landillon, V.; Morel, M.H.; Rouau, X.; Doublier, J.L.; Micard, V. Arabinoxylan gels: Impact of the feruloylation degree on their structure and properties. Biomacromolecule 2005, 6, 309-317. [CrossRef] [PubMed]

13. Mendez-Encinas, M.A.; Carvajal-Millan, E.; Rascon-Chu, A.; Astiazaran-Garcia, H.F.; Valencia-Rivera, D.E. Ferulated Arabinoxylans and Their Gels: Functional Properties and Potential Application as Antioxidant and Anticancer Agent. Oxid. Med. Cell. Longev. 2018, 2018, 2314759. [CrossRef] [PubMed]

14. Herrera-Balandrano, D.D.; Báez-González, J.G.; Carvajal-Millán, E.; Muy-Rangel, D.; Urías-Orona, V.; Martínez-López, A.L.; Marquez-Escalante, J.A.; Heredia, J.B.; Beta, T.; Niño-Medina, G. Alkali-Extracted Feruloylated Arabinoxylans from Nixtamalized Maize Bran Byproduct: A Synonymous with Soluble Antioxidant Dietary Fiber. Waste Biomass Valori 2018, 1, 7. [CrossRef]

15. Tiwari, U.P.; Chen, H.; Kim, S.W.; Jha, R. Supplemental effect of xylanase and mannanase on nutrient digestibility and gut health of nursery pigs studied using both in vivo and in vitro models. Anim. Feed Sci. Tech. 2018, 245, 77e90. [CrossRef]

16. Hopkins, M.J.; Englyst, H.N.; Macfarlane, S.; Furrie, E.; Macfarlane, G.T.; Mcbain, A.J. Degradation of cross-Linked and non-cross-linked arabinoxylans by the intestinal microbiota in children. Appl. Environ. Microbiol. 2003, 69, 6354-6360. [CrossRef]

17. Marquez-Escalante, J.A.; Rascón-Chu, A.; Campa-Mada, A.; Martínez-Robinson, K.G.; Carvajal-Millan, E. Influence of carboxymethylation on the gelling capacity, rheological properties, and antioxidant activity of feruloylated arabinoxylans from different sources. J. Appl. Polym. Sci. 2019, 137, 48325. [CrossRef]

18. Li, S.; Xiong, Q.; Lai, X.; Li, X.; Wan, M.; Zhang, J.; Yan, Y.; Cao, M.; Lu, L.; Guan, J.; et al. Molecular Modification of Polysaccharides and Resulting Bioactivities. Compr. Rev. Food Sci. Food Saf. 2016, 15, 237-250. [CrossRef]

19. Latha, G.M.; Muralikrishna, G. Effect of finger millet (Eleusine coracana, Indaf-15) malt esterases on the functional characteristics of non-starch polysaccharides. Food Hydrocoll. 2009, 23, 1007-1014. [CrossRef]

20. Faulds, C.B.; Zanichelli, D.; Crepin, V.F.; Connerton, I.F.; Juge, N.; Bhat, M.K.; Waldron, K.W. Specificity of feruloyl esterases for water-extractable and water-unextractable feruloylated polysaccharides: Influence of xylanase. J. Cereal Sci. 2003, 38, 281-288. [CrossRef]

21. Dervilly-Pinel, G.; Thibault, J.-F.; Saulnier, L. Experimental evidence for a semi-flexible conformation for arabinoxylans. Carbohydr. Res. 2001, 330, 365-372. [CrossRef]

22. Martínez-López, A.L.; Carvajal-Millan, E.; Sotelo-Cruz, N.; Micard, V.; Rascón-Chu, A.; López-Franco, Y.L.; Lizardi-Mendoza, J.; Canett-Romero, R. Enzymatically cross-linked arabinoxylan microspheres as oral insulin delivery system. Int. J. Biol. Macromol. 2019, 126, 952-959. [CrossRef] [PubMed] 
23. Rosa, N.N.; Barron, C.; Gaiani, C.; Dufour, C.; Micard, V. Ultra-fine grinding increases the antioxidant capacity of wheat bran. J. Cereal Sci. 2013, 57, 84-90. [CrossRef]

24. Malunga, L.N.; Beta, T. Antioxidant capacity of water-extractable arabinoxylan from commercial barley, wheat, and wheat fractions. Cereal Chem. 2015, 92, 29-36. [CrossRef]

25. Anderson, C.; Simsek, S. Mechanical profiles and topographical properties of films made from alkaline extracted arabinoxylans from wheat bran, maize bran, or dried distillers grain. Food Hydrocoll. 2019, 86, 78-86. [CrossRef]

26. Paz-Samaniego, R.; Carvajal-Millan, E.; Sotelo-Cruz, N.; Brown, F.; Rascón-Chu, A.; López-Franco, Y.L.; Lizardi-Mendoza, J. Maize processing waste water upcycling in Mexico: Recovery of arabinoxylans for probiotic encapsulation. Sustainability 2016, 8, 1104. [CrossRef]

27. Gómez Ordóñez, E.; Jiménez Escrig, A.; Rupérez Antón, P. Molecular weight distribution of polysaccharides from edible seaweeds by high-performance size-exclusion chromatography (HPSEC). Talanta 2012, 93, 153-159. [CrossRef]

28. Kale, M.S.; Yadav, M.P.; Chau, H.K.; Hotchkiss, A.T. Molecular and functional properties of a xylanase hydrolysate of corn bran arabinoxylan. Carbohydr. Polym. 2018, 181, 119-123. [CrossRef]

29. Cyran, M.R.; Saulnier, L. Cell Wall Fractions Isolated from Outer Layers of Rye Grain by Sequential Treatment with $\alpha$-Amylase and Proteinase: Structural Investigation of Polymers in Two Ryes with Contrasting Breadmaking Quality. J. Agric. Food Chem. 2005, 53, 9213-9224. [CrossRef]

30. Kacuráková, M.; Wellner, N.; Ebringerova, A.; Hromadkova, Z.; Wilson, R.H.; Belton, P.S. Characterisation of xylan-type polysaccharides and associated cell wall components by FT-IR and FT-Raman spectroscopies. Food Hydrocoll. 1999, 13, 35-41. [CrossRef]

31. Kacuráková, M.; Ebringerová, A.; Hirsch, J.; Hromádková, Z. Infrared study of arabinoxylans. J. Sci. Food Agric. 1994, 66, 423-427. [CrossRef]

32. Buslov, D.K.; Naputski, F.N.; Sushko, N.I.; Torgashev, V.I.; Solov'eva, L.V.; Tsarenkov, V.M.; Zubets, O.V.; Larchenko, L.V. Infrared spectroscopic analysis of the structure of xylans. J. Appl. Spectrosc. 2009, 76, 801-805. [CrossRef]

33. Carvajal-Millan, E.; Guigliarelli, B.; Belle, V.; Rouau, X.; Micard, V. Storage stability of laccase induced arabinoxylan gels. Carbohydr. Polym. 2005, 59, 181-188. [CrossRef]

34. Doublier, J.L.; Cuvelier, G. Gums and Hydrocolloids: Functional Aspects. In Carbohydrates in Food; Eliasson, A.C., Ed.; Science Food and Technology; CRC Press: Boca Raton, FL, USA, 2006.

35. Jia, Y.; He, Y.; Lu, F. The structure-antioxidant activity relationship of dehydrodiferulates. Food Chem. 2018, 269, 480-485. [CrossRef]

36. Malunga, L.N.; Izydorczyk, M.; Beta, T. Effect of water-extractable arabinoxylans from wheat aleurone and bran on lipid peroxidation and factors influencing their antioxidant capacity. Bioact. Carbohydr. Diet Fibre 2017, 10, 20-26. [CrossRef]

37. Shyama Prasad Rao, R.; Muralikrishna, G. Water soluble feruloyl arabinoxylans from rice and ragi: Changes upon malting and their consequence on antioxidant activity. Phytochemistry 2006, 67, 91-99.

38. Mendez-Encinas, M.A.; Carvajal-Millan, E.; Rascón-Chu, A.; Astiazarán-García, H.; Valencia-Rivera, D.E.; Brown-Bojorquez, F.; Alday, E.; Velazquez, C. Arabinoxylan-Based Particles: In Vitro Antioxidant Capacity and Cytotoxicity on a Human Colon Cell Line. Medicina 2019, 55, 349. [CrossRef]

39. Hromádková, Z.; Paulsen, B.S.; Polovkac, M.; Košt'álová, Z.; Ebringerová, A. Structural features of two heteroxylan polysaccharide fractions from wheat bran with anti-complementary and antioxidant activities. Carbohydr. Polym. 2013, 93, 22-30. [CrossRef]

(C) 2019 by the authors. Licensee MDPI, Basel, Switzerland. This article is an open access article distributed under the terms and conditions of the Creative Commons Attribution (CC BY) license (http://creativecommons.org/licenses/by/4.0/). 